\title{
How Human Resource Specialists as Advisors can counsel students who aim to work International Organisations
}

\author{
Manuela Morelli ${ }^{1 *}$, Manke Wang ${ }^{2}$ \\ ${ }^{1}$ International telecommunication Union \\ ${ }^{2}$ United Nations Development Programme
}

*Corresponding Authors: Manuela Morelli, International telecommunication Union

\begin{abstract}
According to the data information about staff demographics published by the United Nations Secretary-General (2019, p. 32-33), the average age for all staff as at 31 December 2018 was 45.7 years. Additionally, the table 1 (Assembly, 2019) shows the demographics of age group also shows that staffs of the UN Secretariat who are in their 20s or younger only takes up to $2.31 \%$ of the total staff population in the UN Secretariat. Although the extremely competitive United Nations (UN) applications might frighten many young professionals, in the recent years, the increasing demands for organizational talents particularly in the UN System also attracts more and more newly graduates to dedicate their careers to international organisations.
\end{abstract}

\section{INTRODUCTION}

Therefore, as human resources specialists believing that talent management has become highly relevant to the business strategies, we wish to express our opinions on career development and provide some suggestions for students who aim to progress in international organisations. Hopefully this article will then represent a source of inspiration and guide for career planning.

Table1. Distribution of all staff of the Secretariat by age as at 31 December 2018

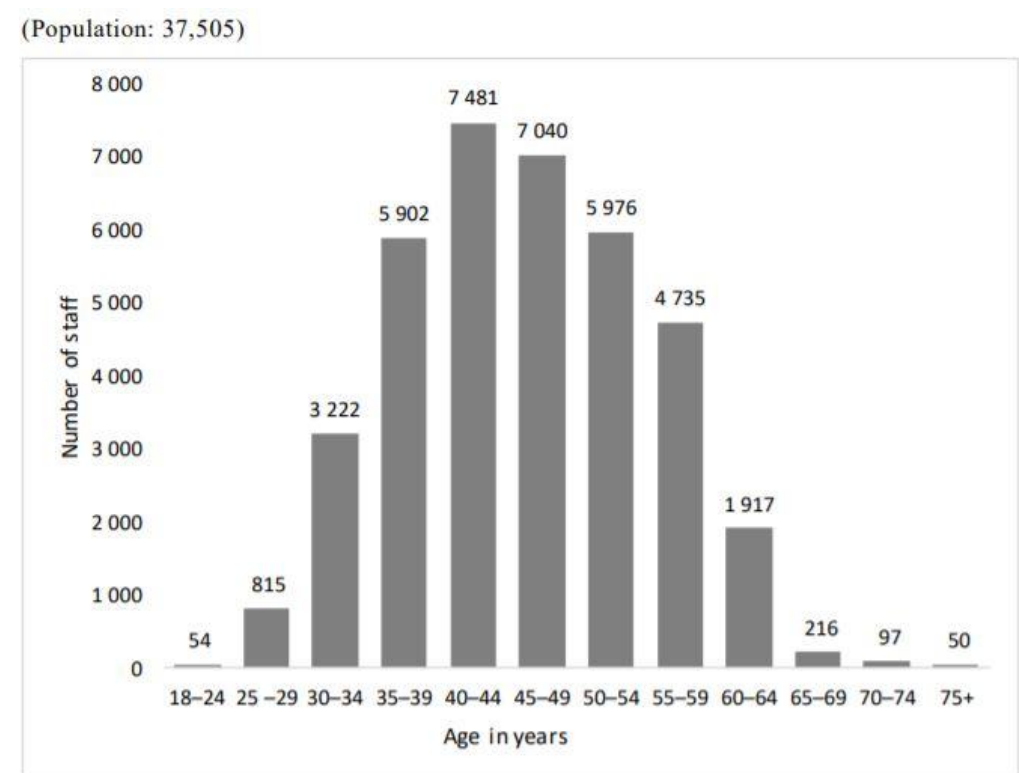

Note. From "Composition of the Secretariat: staff demographics-Report of the Secretary-General.," by UN Assembly, 2019, A/67/329. 32-33 (https://digitallibrary.un.org/record/3809594?ln=en). Copyright.

In this context, the objective is to re-introduce career counselling from the perspective of HR Specialists, and identify how the change of talent management in the international organisations affects the recruitment ofyoung professionals.

\section{Career Counselling}

Career counselling and career guidance is the role of practitioners, who combine giving advice on their topic of expertise with counselling techniques that support clients in making complex decisions 
and facing difficult situations. In addition, career counselling is offered in various settings, including in groups and individually. The focus of career counselling is generally on issues such as career exploration, career change, personal career development and other career related issues, including a wide variety of professional activities which help people deal with career-related challenges, such as career planning, decision making, implementation of career choice, career adjustment, etc. The goal of career counselling is to always help individuals better understand their personalities, interests, values, and skills. This self-understanding will allow individuals to make knowledgeable decisions throughout their lives regarding the world of work, such as requirements, opportunities, and limitations. More precisely, career counselling will equip individuals with the capabilities to make confident choices about their goals to be more successful going forward into the world (Sametz\& Joseph, 2021).Career counsellors work with adolescents seeking to explore career options, experienced professionals contemplating a career change, parents who want to return to the world of work after taking time to raise their child, or people seeking employment.

\section{ROLE AS HR SPECIALISTS}

Recently under the impacts of COVID-19 pandemic, many governments urge the social distances and fully or partially curfews, which negatively affect labour markets and increase the unemployment rates. However, apart from this external factor, generally speaking, the overall unemployment rate among young professionals has been steadily increased over decades. According to information published by the Chinese Ministry of Human Resources and Social Security, 3 million or 50\% of 2013 Chinese college graduates were unemployed. In Saudi Arabia the published general unemployment rate is $10 \%$, although other reports put the figure as high as $25 \%$. South Korea's general unemployment rate in 2013 was $30 \%$. The general unemployment rate in the UK is $6 \%$. In Germany the rate in 2014 was $4.9 \%$, while Spain's rate was as high as $24.1 \%$ in September (Dennis, 2015). Moreover, the table 2 (Plecher, 2020) below shows the seasonally adjusted youth unemployment rate in EU.

Table2. Youth unemployment rate in EU member states as of June 2020

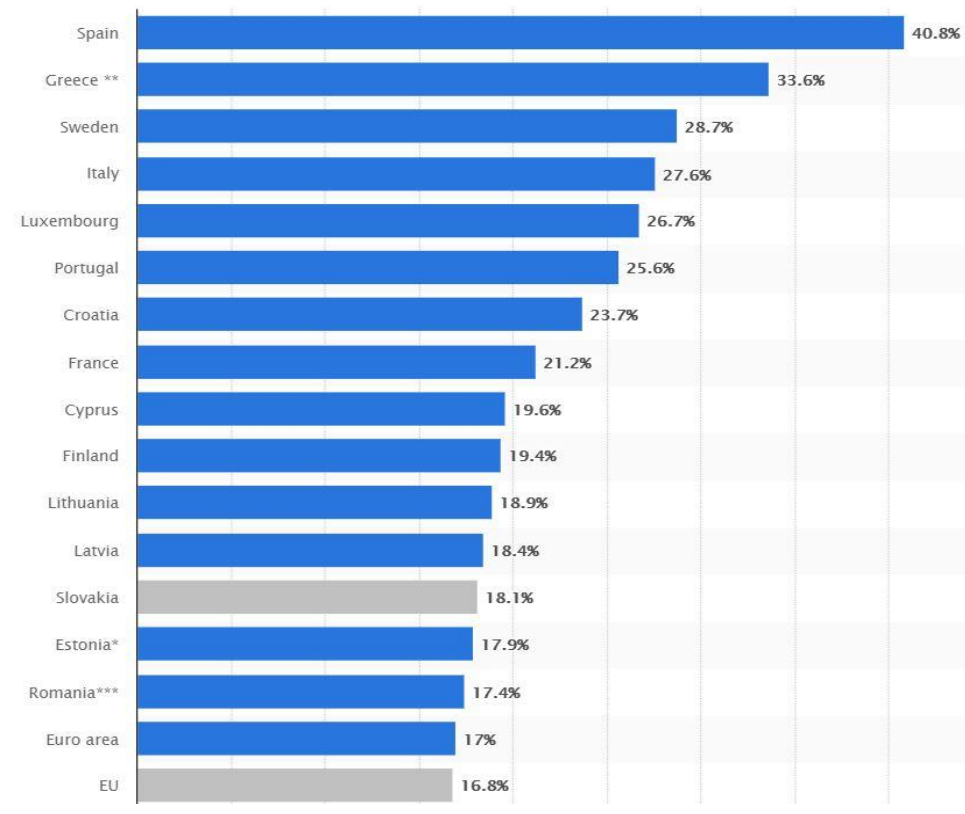

Note. From Youth unemployment rate in EU member states as of June 2020, by R. Plecher, 2020 (https://www.statista.com/statistics/266228/youth-unemployment-rate-in-eu-countries/). Copyright 2020 by Plecher.

What makes the job market for international organizations much difficult for graduate students worldwide?

In order to answer the question above, as career counsellors, we need to first understand besides good academic grades, good written and oral communication skills, what capacities a junior professional needs to obtain to increase the competitiveness in the labour force and what specific to the international organizations. 
In response, career counsellors need to update themselves about what competencies a counsellor should possess and what the more effective methods are nurturing counselling practice. For example, nowadays during the international organisations recruitment for a junior officer, in addition to their professional skills, they are also expected to express the capacities of being able to be adaptable, flexible, a team player with a good interpersonal, leadership and managerial skill.

Particularly, given with the evolution of leadership change management, the understanding of the relationship between management and leadership also develops. For instance, management is traditionally described as to improve economic efficiency and labour productivity. However, over time, the demands of quality management have become increasingly broad. It is no longer limited to analysing and correcting the work activities; instead, managers are expected to distribute organizational resources in a proper way, trust employees, and motivate and lead those who are in charge of the tasks (Cox, 2016). Similarly, Morse and Lorsch (1970) advise that managers need to evaluate the workplace and choose their leadership style based upon the conditions, suggesting that managers have to know how to lead. Consequently, a manager is as well anticipated to inspire the vision and influence in the workplace. Meanwhile, a leader is expected not only to create the vision and lead their subordinates, but also to execute and manage this vision, including providing a plan for changes, a risk management, a strategical analysis, etc. for his employees.

Therefore, the most important element of career counselling is about its adaptation to the trends of a global society and global scope and purposes. As Lorelle with the co-authors (2012) mentions in their article about the important for career counsellor to understand counselling within an international context, the process of globalization is currently impacting the field of counselling, implications and future research directions are examined. Consequently, career counsellors are also required to perceive with a continued and comprehensive understanding of an international attitude of change and inclusion. For example, as the HR officers, knowing that international organisations are committed to creating a diverse and inclusive environment of mutual respect regardless of gender identity, sexual orientation, religious, and ethnic backgrounds or disabilities, we always suggest students to develop corresponding experiences to support them an international and inclusive point of views.

Moreover, several approaches have been undertaken to systemize the variety of professional roles and responsibilities related to career guidance and counselling. In the most recent attempt, the Network for Innovation in Career Guidance and Counselling in Europe (NICE) - a consortium of 45 European institutions of higher education in the field of career counselling - has provided a system of professional roles for guidance counsellors. Each of these five roles is seen as an important facet of the career guidance and counselling profession. Career counsellors performing in any of these roles are expected to behave professionally, e.g. by following ethical standards in their practice (Morelli, 2019).

The NICE Professional Roles (NPR) are:

- The Career Educator "supports people in developing their own career management competences";

- The Career Information \& Assessment Expert "supports people in assessing their personal characteristics and needs, then connecting them with the labour market and education systems";

- The Career Counsellor "supports individuals in understanding their situations, so as to work through issues towards solutions";

- The Programme \& Service Manager "ensures the quality and delivery of career guidance and counselling organisations' services";

- The Social Systems Intervener \& Developer "supports clients (even) in crisis and works to change systems for the better".

\section{Career Counselling Methods}

In addition, there are also a list of assessment tools that could help clients to make realistic career decisions during career counselling. Based on different focuses, these tools generally fall into three categories: interest inventories, personality inventories, and aptitude tests. 


\subsection{Interest Inventory}

The goal of this assessment is to give insight into a person's interests, so that they may have less difficulty in deciding on an appropriate career choice for themselves (Prince, 1998). Interest inventories are usually based on the premise that if a person have similar interests to people in an occupation who like their job, the person will probably like that occupation also. Thus, interest inventories may suggest occupations that the client has not thought of and which have a good chance of being something that the client will be happy with. The most common interest inventory is a measure of vocational interests across six domains: Realistic, Investigative, Artistic, Social, Enterprising, Conventional (Table 3). People often report a mixture of these domains, usually with one predominant domain. Therefore, a career counsellor can use interest inventory test often in helping students and employees become aware of their vocational in career option and selection.

With the help of interest inventory tool, career counsellors seek out via their professional experiences whether or not students' aspirations match with the job vacancies in reality. In addition, HR Specialists as the career counsellors would give a more comprehensive picture about the international organizations compared with the traditional career counsellors. For example, a HR Specialist from UN would definitely have more rights to estimate whether a student's interests correspond with a certain occupation.

Table3. Strong Interest Inventory

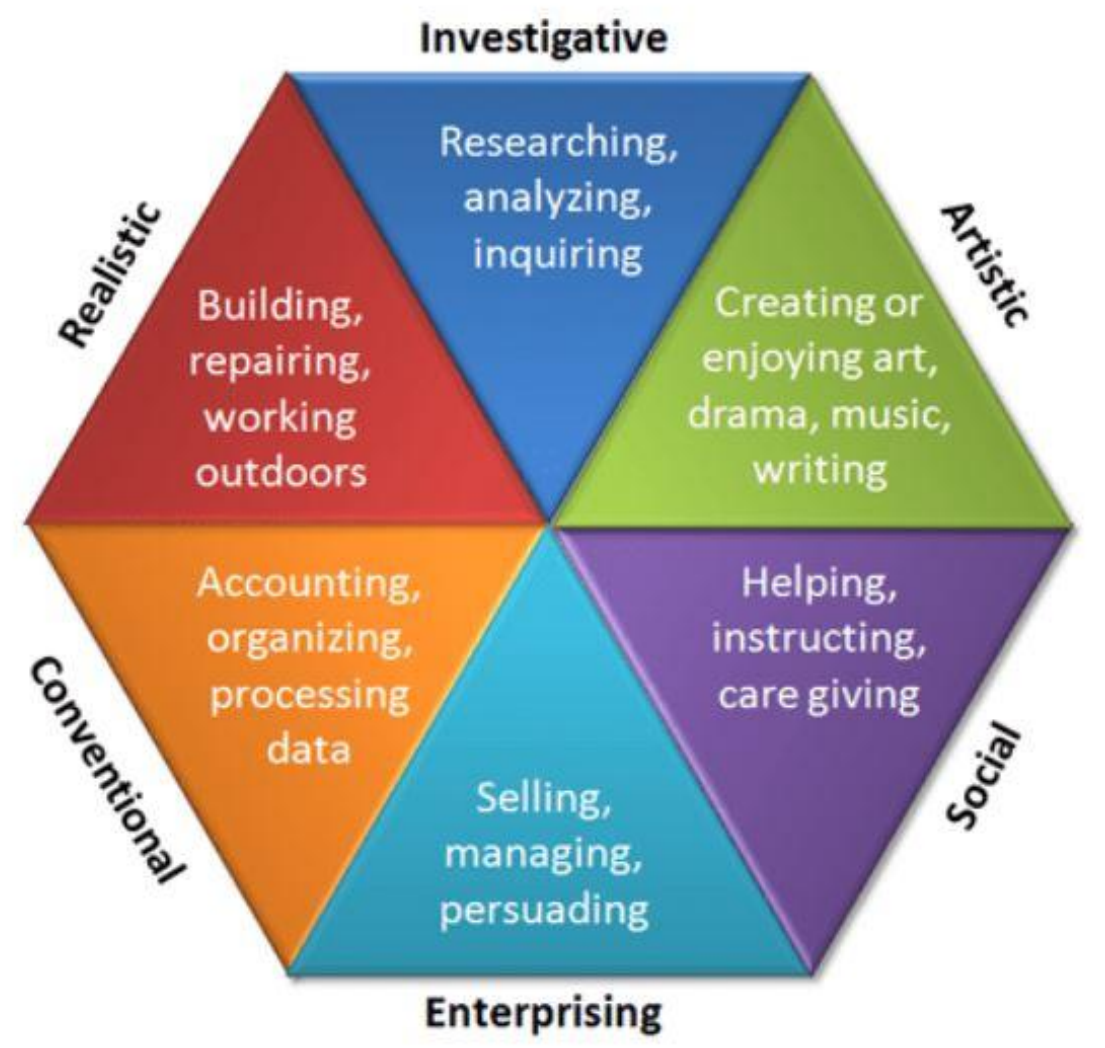

Note. From Strong interest inventory - for career ideas that match interests, by Taylor, 2020 (https://www.amazingpeople.co.uk/strong-interest-inventory/). Copyright 2020 by Taylor.

\subsection{Aptitude Test}

An aptitude test is an assessment tool which assist to determine a client's cognitive ability or personality. Aptitude tests can predict with good odds whether a particular person will be able to besuccessful in a particular occupation. For example, a student who wants to be a physicist is unlikely to succeed if he cannot do the math. An aptitude test will tell him if he is likely to do well in advanced math, which is necessary for physics. There are also aptitude tests which can predict success or failure in many different occupations. They're extremely common in job assessments as they can be used to predict the likelihood of a candidate's success in a job role, whilst eliminating any bias through its standardised administration (AssessmentDay, n.d.). Based on the result of the aptitude test, career 
counsellors can help students to work on their career selection and minimize the options. For instance, the table 4 (KKacademyeduservice, n.d.) below lists some common aptitude tests.

Similarly, compared with traditional career counsellors, for good reason a HR specialist with UN working background could bring more first-hand experience as advice for students. For example, even if a student does not achieve as well in technical tests as other students, a HR specialist might identify something else core capacities from this student, which might be able to allow him or her succeed in the UN.

Table4. Types of Aptitude Test

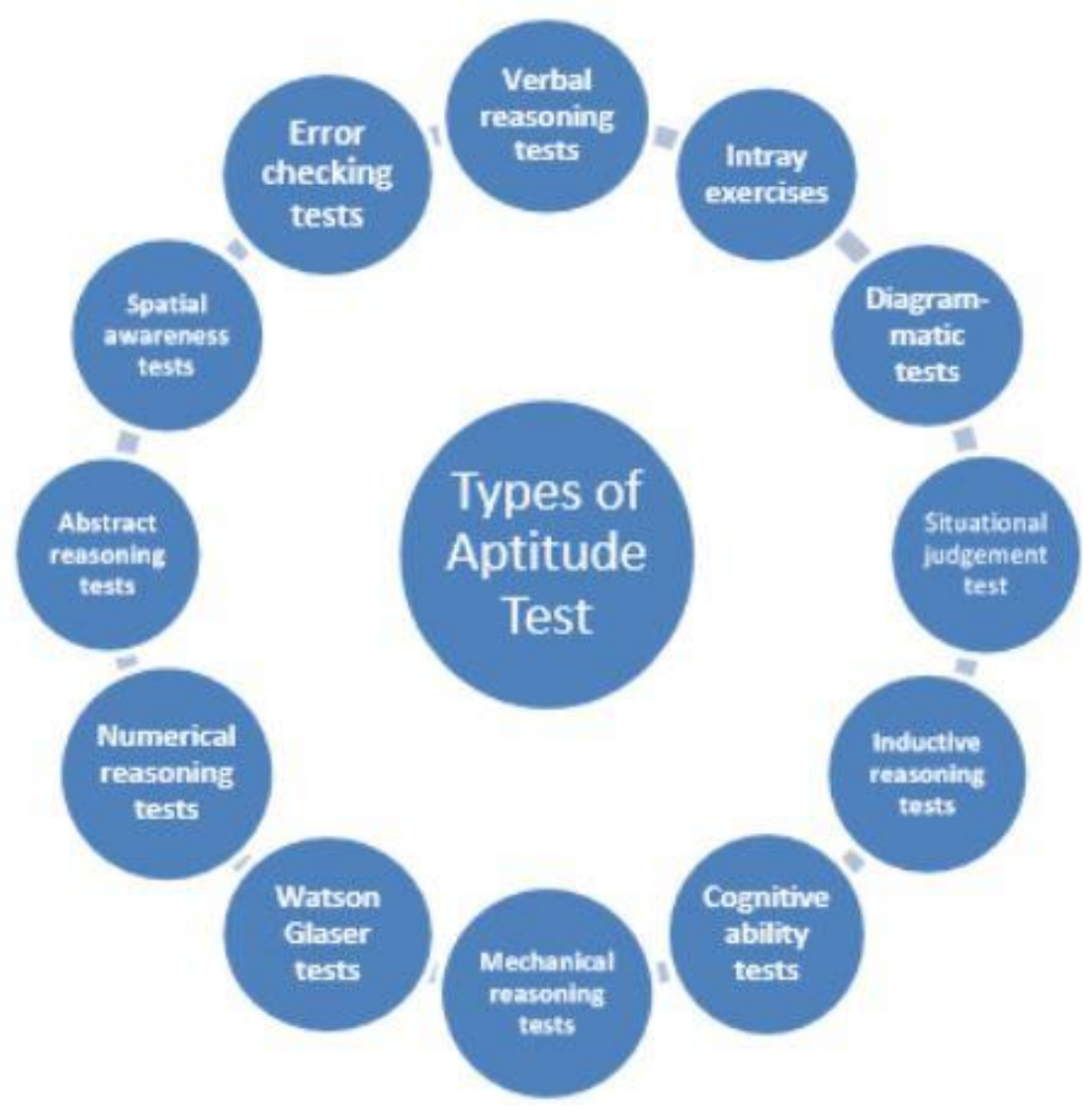

Note. From Types of aptitude test, byKKacademyeduservice, n.d. (https://kkacademys.com/types-of-aptitudetest/). Copyright 2020 by KKacademyeduservice.

\subsection{Personality Inventory}

A personality inventory is a tool of assessing personality trait, sometimes used to help people with career choice. For example, according to Rossier (2015), personality assessment initiates an individual's self-regulatory process and contributes to the overall effectiveness of career interventions when feedback is individualized and stimulates a deconstruction, reconstruction, and construction of the vocational or multiple self-concept. For example, the table 5 (Mckoy, 2019) shows one example of personality inventory. Personality assessments also can promote the reconstruction of a selfconcept more aligned with the perception of the environment about the personality of the counselee, strengthening the reality principle allowing more rational and controlled choices. However, to some extent the use of these inventories for this purpose is questionable, because in any occupation there are people with many different personalities. In general, although the use of this inventory in career counselling is in question, in our point of views, using personality indicators could assist students more or less identify their needs and values for their future occupations.

Again, first-hand experiences would be more useful and convinced for students from a HR Specialist used to work in the international organizations. For example, students would more accept real stories from a HR Specialist's career experience, instead of general textbook knowledge from the tradition career counsellor. 
How Human Resource Specialists as Advisors can counsel students who aim to work International Organisations

Table5. Personality Inventory

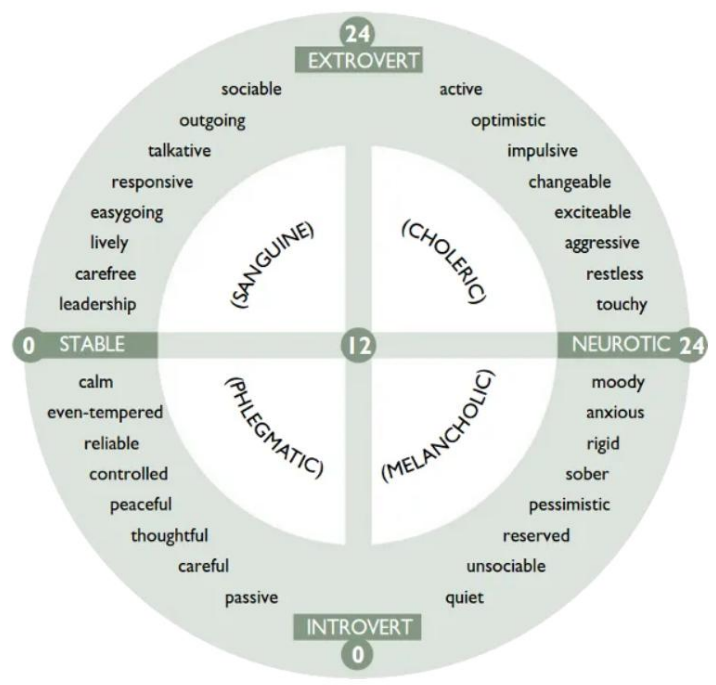

Note. From Eysenck's personality Inventory (EPI) (Extroversion/Introversion), by Mckoy, 2019 (https://stylema nagementexperience.com/test/eysencks-personality-inventory-epi-extroversionintroversion/). Copyright 2020 by Mckoy.

\section{CONCLUSION}

Career counselling led by HR specialists with specific experience in working with young talent creates a more effective relationship than usual career counsellors with their clients, because other than learning or career changes, students sometimes are needed advices that could help them through specific professional and job -life journeys. Therefore, it is clear to say that compared with traditional career counselling, HR specialists as career counsellors are able to offer students with more direct and specific advices from their professional careers, which connects the knowledge from textbooks and real life experiences. We therefore conclude that while traditional career counsellors caninitially help students to first develop a sense of basic perspective, (namely, inclusion, diversity, interpersonal, etc.), which matches the capacities required by the modern international organisations; in a second phase, HR Specialists as career counsellors can start to work on the specific professional and job-life requests with their student clients.

\section{REFERENCES}

[1] Assembly, U. G. (2019). Composition of the Secretariat: staff demographics-Report of the SecretaryGeneral. A/67/329. 32-33. New York: United Nations.

[2] AssessmentDay. (n.d.). Aptitude test practice. Retrieved February 09, 2021, from https://www.asse ssmentday.co.uk/\#: :text=An\%20aptitude\%20test\%20is\%20an,bias\%20through\%20its\%20standardised\% 20administration.

[3] Cox, J.A. (2016). Leadership and Management Roles: Challenges and Success Strategies. AORN Journal, 104-2, 154-160.

[4] Dennis, M. (2015). Universities have a key role to play in career counselling. Retrieved February 08, 2021, from https://www.universityworldnews.com/post.php?story=20150108 180105492

[5] Kkacademyeduservice. (n.d.). Types of aptitude test. Retrieved March 14, 2021, from https://kkacademys.com/types-of-aptitude-test/

[6] Lorelle, S., Byrd, R. J., \& Crockett, S. (2012). Globalization and counseling: Professional issues for counselors. The Professional Counselor: Research and Practice, 2(2), 115-123.

[7] Mckoy, S. (2019). Eysenck's personality Inventory (EPI) (Extroversion/Introversion). Retrieved March 14, 2021, from https://stylemanagementexperience.com/test/eysencks-personality-inventory-epi-extroversioni ntroversion/

[8] Morelli, M. (2019). What is CAREER COUNSELLING? Retrieved February 09, 2021, from https:// manuelamorelli.home.blog/2019/05/13/what-is-career-counseling/

[9] Morse, J. J., \&Lorsch, J. W. (1970). Beyond theory Y (pp. 650-660). Harvard Business Review.

[10] Plecher, H. (2020). Youth unemployment rate in EU member states as of June 2020. Retrieved March 14, 2021, from https://www.statista.com/statistics/266228/youth-unemployment-rate-in-eu-countries/ 
How Human Resource Specialists as Advisors can counsel students who aim to work International Organisations

[11] Prince, J.R. (1998). "Interpreting the Strong Interest Inventory: A case study". The Career Development Quarterly. 46 (4): 339-346.

[12] Rossier, J. (2015). Personality assessment and career interventions.

[13] Sametz, R. R., \& Joseph, M. A. M. (2021). CAREER COUNSELING. 3.

[14] Taylor, D. (2020). Strong interest inventory - for career ideas that match interests. Retrieved March 14, 2021, from https://www.amazingpeople.co.uk/strong-interest-inventory/

\section{AUTHOR'S BIOGRAPHY}

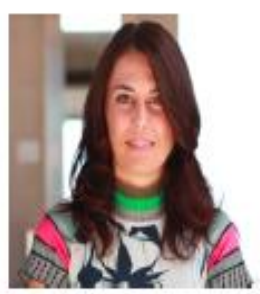

Manuela Morelli's, current role is Head Human Resources Planning and Development at the International telecommunication Union (ITU), the UN Organization dealing with technology for the accomplishment of the 2030 sustainable development goals agenda. Her responsibilities are from performance management to learning and development and succession planning. Manuela is a linguist by background and has a post-graduate in human resources and communication, a PhD in Sociology and a Master Degree in Psychology. She believes that talent acquisition and the potential of young generations is essential for the UN system as a whole.

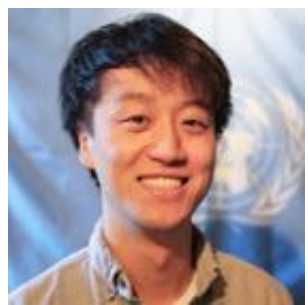

Manke Wang, has a psychology background and a Master Degree in Organizational Science. Currently, he is the Lead Innovation Coordinator at United Nations Development Programme. He believes the talent management plays a crucial role in the business strategy.

Citation: Manuela Morelli, Manke Wang). "How Human Resource Specialists as Advisors can counsel students who aim to work International Organisations" International Journal of Managerial Studies and Research (IJMSR), vol 9, no. 10, 2021, pp. 01-07. doi: https://doi.org/10.20431/2349-0349.0910001.

Copyright: () 2021 Authors. This is an open-access article distributed under the terms of the Creative Commons Attribution License, which permits unrestricted use, distribution, and reproduction in any medium, provided the original author and source are credited. 